\title{
Transcriptome profiling confirmed correlations between symptoms and transcriptional changes in RDV infected rice and revealed nucleolus as a possible target of RDV manipulation
}

Liang Yang ${ }^{1,2+}$, Zhenguo Du ${ }^{1,4 \dagger}$, Feng Gao ${ }^{3}$, Kangcheng $\mathrm{Wu}^{1,2}$, Lianhui Xie ${ }^{1,2}, \mathrm{Yi}_{\mathrm{i}} \mathrm{Li}^{3}$, Zujian $\mathrm{Wu}^{1,2^{*}}$ and Jianguo $\mathrm{Wu}^{1,2,3^{*}}$

\begin{abstract}
Background: Rice dwarf virus (RDV) is the causal agent of rice dwarf disease, which limits rice production in many areas of south East Asia. Transcriptional changes of rice in response to RDV infection have been characterized by Shimizu et al. and Satoh et al.. Both studies found induction of defense related genes and correlations between transcriptional changes and symptom development in RDV-infected rice. However, the same rice cultivar, namely Nipponbare belonging to the Japonic subspecies of rice was used in both studies.

Methods: Gene expression changes of the indica subspecies of rice, namely Oryza sativa L. ssp. indica cv Yixiang2292 that show moderate resistance to RDV, in response to RDV infection were characterized using an Affymetrix Rice Genome Array. Differentially expressed genes (DEGs) were classified according to their Gene Ontology (GO) annotation. The effects of transient expression of Pns11 in Nicotiana benthaminana on the expression of nucleolar genes were studied using real-time PCR (RT-PCR).
\end{abstract}

Results: 856 genes involved in defense or other physiological processes were identified to be DEGs, most of which showed up-regulation. Ribosome- and nucleolus related genes were significantly enriched in the DEGs. Representative genes related to nucleolar function exhibited altered expression in N. benthaminana plants transiently expressing Pns 11 of RDV.

Conclusions: Induction of defense related genes is common for rice infected with RDV. There is a co-relation between symptom severity and transcriptional alteration in RDV infected rice. Besides ribosome, RDV may also target nucleolus to manipulate the translation machinery of rice. Given the tight links between nucleolus and ribosome, it is intriguing to speculate that RDV may enhance expression of ribosomal genes by targeting nucleolus through Pns11.

Keywords: RDV, Transcriptome profiling, Pns11, Nucleolus

\footnotetext{
*Correspondence: wuzujian@126.com; wujianguo81@126.com

${ }^{\dagger}$ Equal contributors

${ }^{1}$ Key Laboratory of Plant Virology of Fujian Province, Institute of Plant

Virology, Fujian Agriculture and Forestry University, Fuzhou, Fujian 350002,

China

${ }^{2}$ Key Laboratory of Biopesticide and Chemibiology of Ministry of Education,

Fujian Agriculture and Forestry University, Fuzhou, Fujian 350002, China

Full list of author information is available at the end of the article
} 


\section{Background}

Viruses are obligate intracellular pathogens. They hijack host functions, divert host resources and suppress host defense responses to achieve successful infection [1]. These involve an array of interactions with cellular factors, which, inevitably or coincidentally, often lead to host physiological disorders manifested by a variety of disease symptoms [2,3]. Understanding molecular details from infection of a virus to symptom development of the host is one major mission of plant virologists. Transcriptome profiling has been used extensively in the past decade to understand mechanisms underlying plant-virus interaction $[4,5]$. Transcriptional response of plants to virus infection is shown to vary depending on virus species, virus strains and the genetic backgrounds of host plants [6-8]. However, it shows a tight link with phenotypes and thus is useful to reveal how a virus colonizes a host, how a host mounts a defense response against a virus, and how a compatible virus-host interaction results in disease symptoms [6-8]. Also, these studies find that some genes may be commonly regulated by different viruses in different host plants [9]. For example, a set of ribosomal genes have been shown to be up-regulated in Arabidopsis, Nicotiana benthamiana and rice infected with Turnip mosaic virus (TuMV), Plum pox potyvirus (PPV) and Rice stripe virus (RSV), respectively [10-12].

Rice, one of the main crop plants as well as a model for monocot plant research [13], is host to many viruses. Among them, Rice dwarf virus (RDV), a member of the genus Phytoreovirus in the family Reoviridae, is one of the most widespread and disastrous rice-infecting viruses causing great yield reduction in south East Asia [14-16]. RDV is transmitted in a propagative and circulative manner by leafhoppers (Nephotettix spp.) [17]. Typical symptoms associated with RDV infection include severe dwarfism, increased tilling and white chlorotic specks on the infected leaves [18].

RDV are icosahedral double-shelled particles of approximately $70 \mathrm{~nm}$ in diameter. The genome of RDV is composed of 12 segments of double stranded RNAs, which are named S1-S12, respectively, according to their migration during sodium dodecyl sulfate-polyacrylamide gel electrophoresis. S1, S2, S3, S5, S7, S8, and S9 encode seven structural proteins, namely, P1, P2, P3, P5, P7, P8, and P9, respectively. $\mathrm{P} 1$, a putative RNA polymerase; $\mathrm{P} 5$, a putative guanylyltransferase; and P7, a nonspecific nucleic acid binding protein form the core of RDV together with viral dsRNAs [19]. P3 and P8 are major components of the inner and outer protein shells that encapsidate the core, respectively [20,21]. P2 and P9 are minor components of the outer capsid [22,23]. The structural features and the process of assembly of RDV virions have been well studied $[24,25]$. Besides structural proteins, RDV encodes at least five non-structural proteins, namely Pns4, Pns6, Pns10, Pns11, and Pns12, respectively. Pns6, Pns11 and Pns12 are matrix proteins of viroplasm, which is the putative site of viral replication [26]. Pns4 is a phosphoprotein and is localized around the viroplasm matrix in insect cells [27]. Several proteins of RDV have been shown to play specific roles in RDV-rice interaction. For example, Pns6 was identified as a viral movement protein and Pns10 as a RNA silencing suppressor of RDV [28,29]. P2 interacts with ent-kaurene oxidases of rice, which leads to reduced biosynthesis of gibberellins and rice dwarf symptoms [30].

In this study, the transcriptome of the indica subspecies of rice, namely Oryza sativa L. ssp. indica cv Yixiang2292, in response to RDV infection was profiled using Affymetrix GeneChips, which contains probes representing the entire genome of rice [13] (www.affymetrix.com). Our results further confirm the notion that induction of defense related genes is common for rice infected with RDV and there are correlations between transcriptional changes and symptom development in RDV-infected rice.

\section{Results}

Transcriptome profiling of RDV-infected rice

For transcriptome analysis, rice seedlings were virus- or mock- inoculated. Total RNAs were extracted at 22 days post inoculation (dpi), i.e. the earliest time when infection could be confirmed by the appearance of symptoms. The GeneChip hybridization and scanning were performed at the Microarray Resource Laboratory at Beijing CapitalBio Corporation, Beijing, China, in which GeneChip microarray service was certificated by Affymetrix. The microarray data were analyzed using SAM (Significant Analysis of Microarray) software. Deferentially expressed genes (DEGs) were identified with the criteria of fold changes $>1.5$ and false positive rate $(q$-value $)<0.058$. In this way, a total of 856 genes were identified to be DEGs, in which 838 genes were upregulated and 18 downregulated. A list of the genes identified is presented in Additional file 1: Table S1.

\section{Classification of DEGs}

To get an overview of the functions of the DEGs, DEGs were classified according to their function. The classification was done manually based on gene annotations (http://rice.plantbiology.msu.edu/) and literature searching. Among the 856 DEGs, 275 genes have no annotations or were simply annotated as hypothetical protein/ expressed protein. These genes were not analyzed further in our study. The remaining 581 genes were classified into 14 non-redundant categories (Figure 1, Additional file 2: Table S2). As shown in Figure 1, unclassified genes formed the largest group. They referred to genes that were difficult to be classified into groups. Of the genes that have 


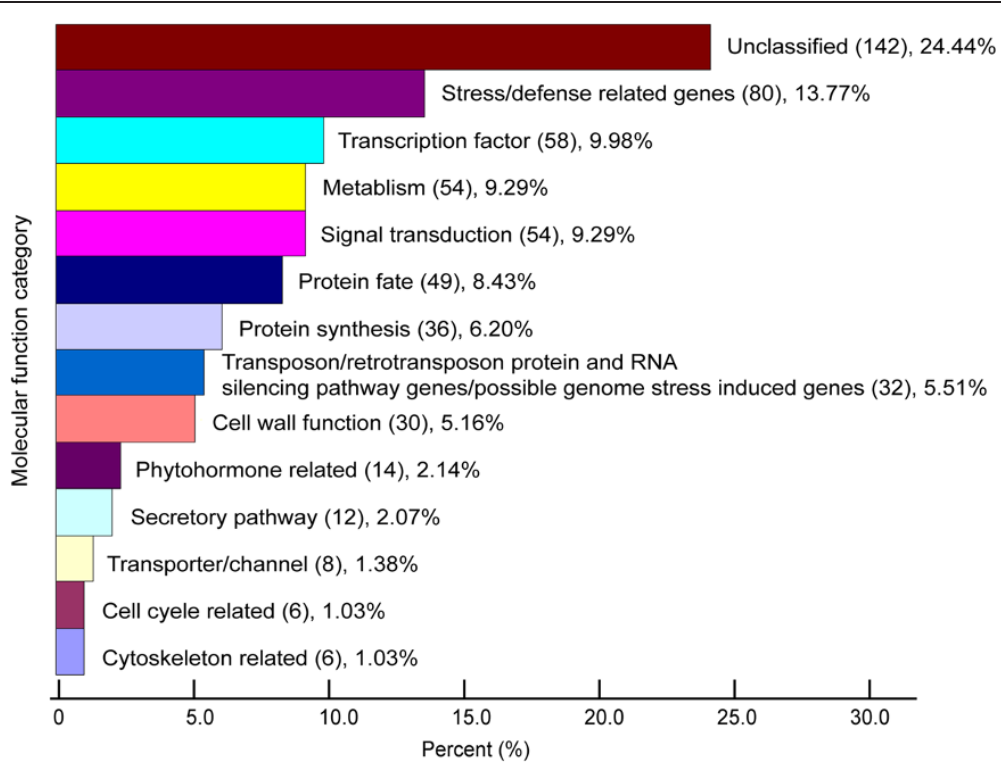

Figure 1 An overview of the functional classification of the $\mathbf{5 8 1}$ RDV responsive genes. Number of genes and relative percentage for each category were indicated. For a list of the genes in each category see Additional file 2: Table $\mathbf{S 2 .}$

been classified, three categories are of particular interests to us.

\section{Defense/stress related genes}

This set of genes forms the second largest group. They include PR genes, markers of defense responses; several genes encoding WRKY transcription factors, key regulators of defense responses [31]; L-ascorbate oxidase and Peroxidase genes, important modulators of oxidative stress, among others [32].

\section{Protein synthesis related genes}

In all, 36 RDV responsive genes were classified into this category (Figure 1). The large number of this category was due mostly to ribosomal genes. These included 27 genes encoding cytosolic ribosomal subunits, 2 mitochondrial ribosomal genes and 1 gene encoding a chloroplast ribosome precursor. Other genes belonging to this category include those involved in translation initiation, termination and tRNA metabolism. All these genes were upregulated.

\section{Transposon/retrotransposon protein/RNA silencing pathway genes/possible genome stress related genes}

Surprisingly, a large number of genes encoding transposon/ retrotransposon-related proteins were affected (Figure 1). Normally, tansposon or transposon-related genes are transcriptional inert because of epigenetic regulations. Altered expression of these kinds of genes indicated that the rice genome was suffering a genomic stress. Indeed, genes involved in DNA recombination (AK063836, encoding a Single-strand binding protein family protein; BQ908269, encoding a RuvB-like 1 protein; AB079873, encoding a Meiotic recombination protein DMC1 homolog.), DNA repair (AK101485, encoding a DNA repair ATPase) and chromosome assembly (AK108572, encoding a complex 1 protein containing protein) were all upregulated. The RNA silencing pathway, which plays a pivotal role in epigenetic regulations, was also significantly affected. Genes functioning in this pathway such as $A G O s, R D R s$ showed marked up-regulation (Figure 1, Additional file 2: Table S2).

\section{GO enrichment analysis}

DEGs were also classified according to Gene Ontology (GO) cellular component, which indicates the location or suspected location of a gene in a cell [33]. As shown in Table 1, six GO cellular component terms were significantly enriched in DEGs, cell wall, nucleus, ribosome, cytosol, extracellular region, and nucleolus $(p<0.01)$. We were interested in the concomitant enrichment of the two GO terms Ribosome and Nucleolus, because nucleolus is the site of ribosomal RNA synthesis and ribosome maturation.

\section{Verification of the microarray data}

The accuracy of the microarray data was verified by qRT-PCR. Seventeen genes including ribosomal, nucleolar and transposon/retrotransposon related genes and genes involved in RNA silencing, auxin signal, and cell wall function were selected. The CP gene of RDV was used to as a control. As shown in Figure 2 and Table 2, qRT-PCR results of all 17 RDV responsive genes selected were consistent with the microarray data. 
Table 1 Results of GO cellular component analysis with MAS 2.0 system

\begin{tabular}{|c|c|c|c|c|}
\hline GO number & Cellular component & Total change genes & $p$-value & $q$-value \\
\hline GO:0005618 & Cell wall & 112 & 0.0 & 0.0 \\
\hline GO:0005634 & Nucleus & 101 & 0.0 & 0.0 \\
\hline GO:0005840 & Ribosome & 24 & 0.0 & 0.0 \\
\hline GO:0005829 & Cytosol & 21 & $1.0 \mathrm{E}-6$ & $3.0 \mathrm{E}-6$ \\
\hline GO:0005576 & Extracellular region & 14 & 3.64E-4 & $5.24 \mathrm{E}-4$ \\
\hline GO:0005730 & Nucleolus & 20 & 0.0014 & 0.0018 \\
\hline GO:0005886 & Plasma membrane & 23 & 0.0128 & 0.0148 \\
\hline GO:0016020 & Membrane & 103 & 0.0152 & 0.016 \\
\hline GO:0005740 & Mitochondrial envelope & 2 & 0.1273 & 0.1182 \\
\hline GO:0005794 & Golgi apparatus & 4 & 0.1314 & 0.1217 \\
\hline GO:0005635 & Nuclear envelope & 3 & 0.2492 & 0.2231 \\
\hline GO:0005856 & Cytoskeleton & 7 & 0.3283 & 0.2924 \\
\hline GO:0005783 & Endoplasmic reticulum & 2 & 0.3565 & 0.3161 \\
\hline GO:0016023 & Cytoplasmic membrane-bound vesicle & 62 & 0.4074 & 0.3457 \\
\hline GO:0005773 & Vacuole & 3 & 0.5308 & 0.4267 \\
\hline GO:0005654 & Nucleoplasm & 1 & 0.5373 & 0.4314 \\
\hline GO:0005777 & Peroxisome & 1 & 0.671 & 0.5287 \\
\hline GO:0009579 & Thylakoid & 12 & 0.6852 & 0.5375 \\
\hline GO:0005739 & Mitochondrion & 137 & 0.9989 & 0.5485 \\
\hline GO:0009536 & Plastid & 65 & 1.0 & 0.5485 \\
\hline GO:0005622 & Intracellular & 10 & 1.0 & 0.5485 \\
\hline GO:0005737 & Cytoplasm & 82 & 1.0 & 0.5485 \\
\hline GO:0005575 & Cellular_component & 3 & 1.0 & 0.5485 \\
\hline GO:0005623 & Cell & 8 & 1.0 & 0.5485 \\
\hline
\end{tabular}

The nucleoli were affected in RDV-infected rice

Transmission electron microscopy was used to determine if there are any pathologic changes related to nucleoli in RDV-infected cells. As shown in Figure 3, two forms of nucleoli were observed in infected or control rice plants: small, round and concentrated electron-dense spheres (type 1) and big, irregular sub-cellular compartments filled with dispersive electron-dense aggregates (type 2). Statistical analysis confirmed that the number of type $2 \mathrm{nu}$ cleolus in RDV infected rice $(61 \% \sim 67 \%)$ was higher than that of type 1 , whereas in control rice plants, the number of type 1 nucleolus was higher than that of type $2(27 \% \sim 33 \%)$.

RDV Pns11 regulates the transcript levels of nucleolus-related genes in tobacco cells

The finding that many nucleolus targeting genes were de-regulated in RDV infected rice suggests that RDV may manipulate nucleolar functions. The subcellular localization of all RDV-encoded proteins was predicted by Predict NLS (http://www.biologydir.com/nls-prediction/p1.html). Only Pns11 has a nuclear localization signal (NLS) with NLSIand NLSIIdomains belonging to the bipartite NLS [34] (Figure 4A). So Pns11 may be responsible for alteration of nucleolar genes in RDVinfected rice. To test this possibility, the expression levels of two nucleolar genes were studied in $N$. benthamiana leaves expressing RDV Pns11. qRT-PCR results revealed that the two genes (AB207972 and AM269909 encoding fibrillarin) were upregulated significantly. As controls, two genes related to defense (Glucan endo-1,3-beta-glucosidase GII precursor, M60402 and M60403) showed reduced expression, whereas two genes functioning in RNA silencing (DQ321488 and DQ321489) remained unchanged (Figure $4 \mathrm{~B})$.

\section{Discussion}

The transcriptome of RDV infected rice plants was profiled in this study. A number of genes are differentially expressed in RDV infected rice. Changes of most of these genes are consistent with previous studies carried out using $N$. benthamiana or Arabidopsis thaliana [4,10,11,35-39]. Also, we find induction of a set of defense related genes including PR genes, WRKY transcription 


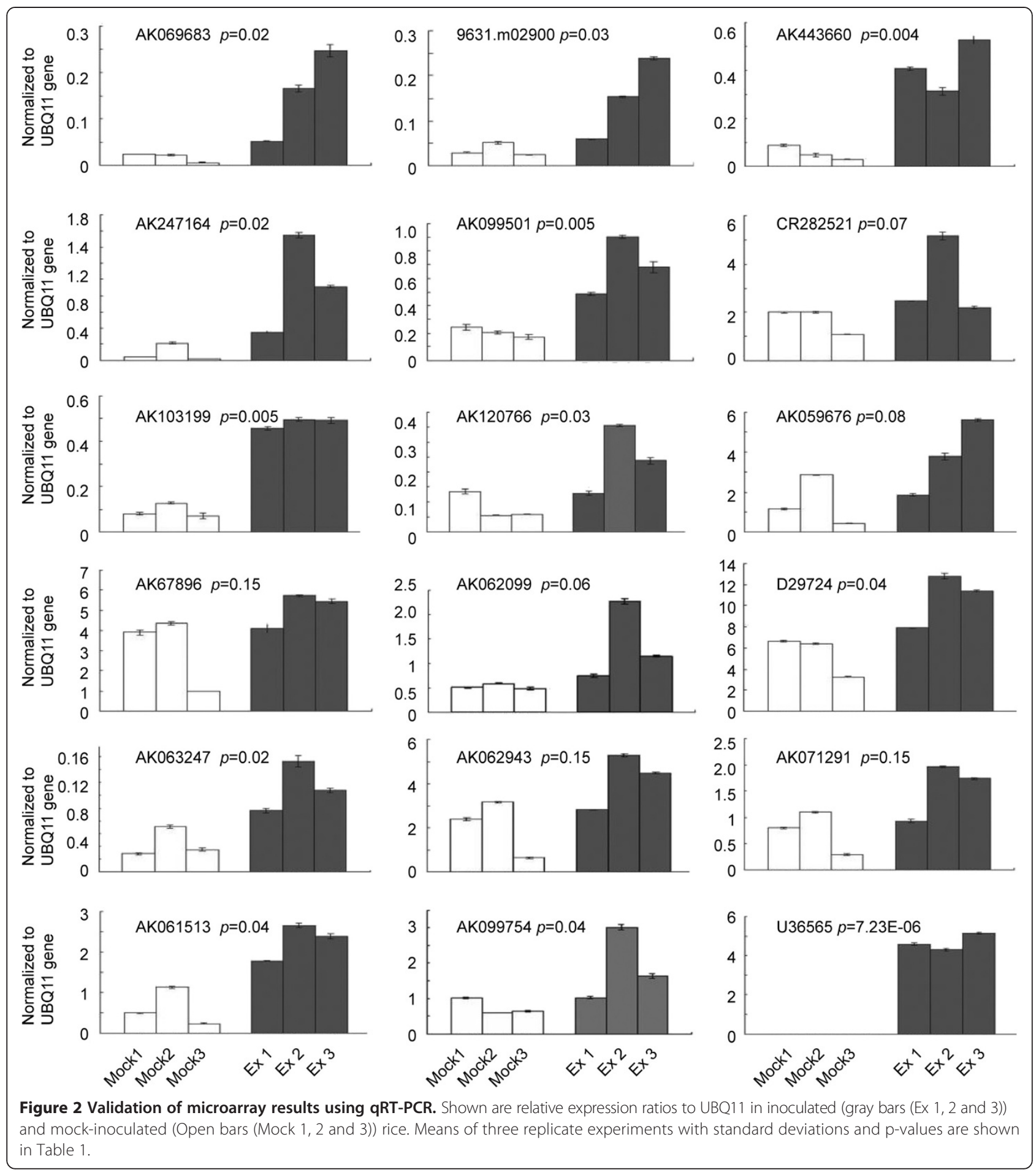

factors and several genes functioning in RNA silencing. This is consistent with reports of Shimizu et al. [9] and Satoh et al. [7] showing that increased expression of defense related genes may be a common response of rice infected with RDV $[7,40]$. However, our results indicate that RDV induced the expression of far more genes than it suppressed. This is in sharp contrast to the report of
Shimizu et al. [40]. Multiple resons may be responsible for the inconsistency. But the most plausible one is that transcriptome change in response to RDV infection is host-specific. In the study of Shimizu et al. [40], the Japonica subspecies of rice, namely Oryza sativa $L$. $c v$. Nipponbare, was used, whereas in this study, the indica subspecies of rice, namely Oryza sativa L. ssp. 
Table 2 Real-time PCR to verify expression pattern of differentially expressed genes from the microarray experiment (for a list of these genes primer sequence, see Additional file 2: Table S2)

\begin{tabular}{|c|c|c|c|c|c|}
\hline \multirow[t]{2}{*}{ GB.accession } & \multicolumn{2}{|c|}{ Fold change $(E x /$ Mock $) \pm S D$} & \multirow[t]{2}{*}{$p$-value ${ }^{\mathrm{B}}$} & \multirow[t]{2}{*}{$p$-value ${ }^{\mathrm{A}}$} & \multirow[t]{2}{*}{ Description } \\
\hline & Microarray & qRT-PCR & & & \\
\hline AK069685 & $5.4983 \pm 1.581$ & $6.6246 \pm 3.6546$ & 0 & 0.0204 & Piwi domain containing protein, expressed \\
\hline 9631.m02900 & $2.6141 \pm 0.7001$ & $2.9988 \pm 0.530$ & 0 & 0.0316 & Small nuclear ribonucleoprotein G, putative, expressed \\
\hline AF443600 & $6.2009 \pm 2.7810$ & $6.5142 \pm 2.1441$ & 0.0042 & 0.0045 & Glucan endo-1,3-beta-glucosidase GII precursor, putative, expressed \\
\hline AF247164 & $6.1081 \pm 6.8408$ & $6.7585 \pm 11.4824$ & 0.0236 & 0.0235 & Alpha-expansin 4 precursor, putative, expressed \\
\hline AK099501 & $2.1007 \pm 0.9030$ & $2.4711 \pm 0.5329$ & 0.0261 & 0.005 & Ribonucleoprotein, putative, expressed \\
\hline CR282531 & $1.7015 \pm 0.2375$ & $1.4174 \pm 0.5866$ & 0.0303 & 0.0694 & 605 acidic ribosomal protein P2A, putative, expressed \\
\hline AK103199 & $3.2899 \pm 2.5965$ & $4.0319 \pm 3.4615$ & 0.0302 & 0.0057 & Transposon protein, putative, CACTA, En/Spm sub-class, expressed \\
\hline AK062099 & $1.6257 \pm 0.3806$ & $1.7461 \pm 0.3890$ & 0.0308 & 0.0601 & Ribosomal L28e protein family protein, expressed \\
\hline AK059679 & $1.8421 \pm 0.303$ & $1.9076 \pm 0.9539$ & 0.0308 & 0.0892 & 605 ribosomal protein L38, putative, expressed \\
\hline AK067896 & $1.6171 \pm 0.2825$ & $1.3415 \pm 0.6274$ & 0.04342 & 0.1508 & 605 ribosomal protein $L 6$, putative, expressed \\
\hline AK120766 & $1.7459 \pm 0.5397$ & $2.1115 \pm 0.8514$ & 0.04342 & 0.0293 & Piwi domain containing protein, expressed \\
\hline D29724 & $1.529 \pm 0.2032$ & $1.51084 \pm 0.2562$ & 0.04342 & 0.0408 & $\begin{array}{l}\text { Peptide chain release factor } 2 \text {, putative, expressed, } 605 \text { ribosomal } \\
\text { protein } L 38 \text {, putative, expressed }\end{array}$ \\
\hline AK063247 & $2.5979 \pm 1.4057$ & $2.0925 \pm 2.0497$ & 0.04342 & 0.0197 & Auxin-induced protein TGSAUR12, putative, expressed \\
\hline AK062943 & $1.5919 \pm 0.0932$ & $1.5679 \pm 1.0226$ & 0.0483 & 0.0986 & $40 \mathrm{~S}$ ribosomal protein $\mathrm{S} 15 \mathrm{a}$, putative, expressed \\
\hline AK071291 & $1.6782 \pm 0.3353$ & $1.5959 \pm 0.6893$ & 0.0483 & 0.0831 & Fibrillarin-2, putative, expressed \\
\hline AK061513 & $2.5152 \pm 0.6761$ & $2.8184 \pm 1.9757$ & 0.0588 & 0.0434 & Nucleoid DNA-binding protein cnd41, putative, expressed \\
\hline AK099754 & $1.7647 \pm 0.2432$ & $1.7471 \pm 0.2758$ & 0.0588 & 0.0487 & Nucleolar protein NOP5, putative, expressed \\
\hline U36565 & - & $4.8787 \pm 2.0832$ & - & 7.23E-06 & Rice dwarf virus coat protein mRNA, complete cds \\
\hline UBQ11* & - & - & - & 0.1955 & \\
\hline
\end{tabular}

Notice: ${ }^{A} p$-value form microarray experiment; ${ }^{B} p$-value from $q \mathrm{RT}-\mathrm{PCR}$; ${ }^{*}$ Rice UBQ11 was used as a control for $q \mathrm{RT}$-PCR.

indica cv Yixiang2292, was used. Yixiang 2292, the rice variety used in this study, shows moderate resistance to RDV infection. It can develop typical symptoms of RDV infection, but the symptoms are not as severe as those of more susceptible varieties. A number of recent studies have demonstrated that there is a co-relation between symptom severity and transcriptional alteration in different virus-host combinations [6-8,41].

Many genes related to protein synthesis (Figure 1) were found and the GO term Ribosome was significantly enriched in the DEGs (Table 1). This is consistent with several studies showing that up-regulation of ribosomal genes and a set of other genes involved in protein synthesis could be a general response of plants to many viruses [10-12]. It has been suggested that this may be a strategy used by the virus to enhance the capacity of the cell to synthesize proteins [10-12].

As a two-subunit ribonucleoprotein complex comprising tens of ribosomal proteins and four species of ribosomal RNAs, the biogenesis of ribosome is one of the most energy consuming cellular processes [42-44]. So it is anticipated that synthesis of ribosomal components should be downregulated in response to environmental cues, as it has been shown in yeast and in Arabidopsis $[45,46]$. Therefore, increased expression of ribosomal genes in virus infected plants may be a result of specific virushost interaction.

Here, we show that RDV infection also causes a significant alteration of many nucleolar genes (Table 1). The fact that RDV Pns11 has a nuclear localization signal and induces the expression of nucleolus-related genes in tobacco (Figure 4) and the observation that nucleoli seems to be affected in RDV infected rice (Figure 3) support the notion that this alteration is specific and may be useful for RDV. Nucleolus is the site of ribosomal RNA synthesis and processing and ribosome maturation [47]. Therefore, it is possible that, besides ribosome, RDV may also target nucleolus to manipulate the translation machinery of rice. Interestingly, there is evidence that certain nucleolar components or its overall state play a crucial role in controlling ribosomal gene expression and biogenesis $[46,48]$. So it is intriguing to speculate that RDV may specifically target nucleolus to enhance expression of ribosomal genes. In this regard, it is worth noting that a number of viruses, including many RNA viruses whose primary site of replication is the cytoplasm, encode special proteins to target nucleolus [49]. It would be very interesting to test the link between nucleolar targeting of these viruses and ribosome biogenesis of their hosts. 


\section{Oryza sativa ssp.japonica Oryza sativa L. ssp. indica}

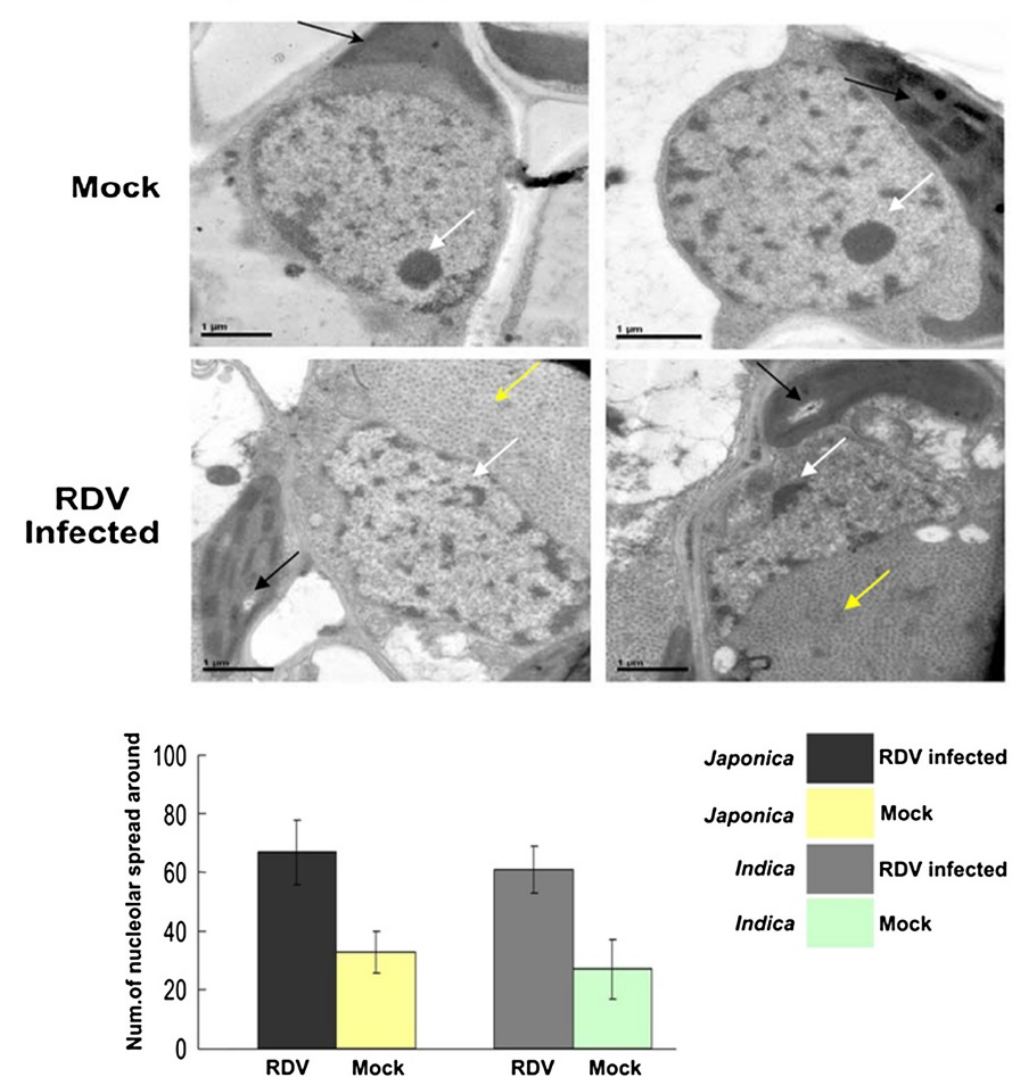

Figure 3 The structure of nucleolus in RDV-infected rice. White arrowhead: Nucleolus; Black arrowhead: Chloroplast; Yellow arrowhead: RDV Virion. Rectangle: the biological statistics of number of nucleolar spread around.

Besides ribosomal genes, malfunction of nucleolus may be responsible for altered expression of many other genes detected in this study. For example, emerging evidence suggests that nucleolus might play a role in the small interfering RNA (siRNA) pathway $[47,50]$. Therefore, many genes controlled by siRNAs may be altered because of malfunction of nucleolus in RDV infected rice. Consistent with this, we found a large number of genes encoding transposon/retrotransposon-related proteins in the DEGs (Figure 1). It is well known that tansposon or transposon-related genes are transcriptionally controlled by epigenetic modifications, in which siRNAs play an important role [51]. To our knowledge, altered expression of transposon/retrotransposon-related genes has never been reported in virus infected plants. However, we do not favor the possibility that this is specific to RDV. Instead, DEGs were classified automatically using web-based tools in most previous studies. In this way, transposon/retrotransposon-related genes tend to be classified into "unknown" genes and be excluded for further analysis.

\section{Materials and methods}

\section{Sources of virus and insects}

RDV Fujian isolate, China, was maintained in "Taizhong$1^{\prime \prime}$ rice plants grown in greenhouses at $25 \pm 3^{\circ} \mathrm{C}, 55 \pm 5 \%$ $\mathrm{RH}$ and under natural sunlight. Insects (Nephotettix cincticeps) source: high infectious green rice leafhoppers cultured in our lab with five generations of artificial rearing on rice seedlings.

\section{Plant growth and inoculation}

Seeds (Oryza sativa L. ssp. indica cv Yixiang2292) were sowed and germinated on a pot $(60 \mathrm{~mm}$ in diameter and $50 \mathrm{~mm}$ in height) that had been filled with commercial soil mixture (FAFARD SOILS, Southern Agricultural Insecticides Inc Palmetto, FL, 34221). Rice seedlings were subjected to a two-day inoculation using high infectious green rice leafhoppers or virus-free insects (for mock inoculation) by the one test tube-one-seedling method. Inoculated seedlings were transplanted to an iron dish filled with cultivation layer soil of experimental farmland. They were kept in a south-facing greenhouse at $25 \pm 3^{\circ} \mathrm{C}$ with 


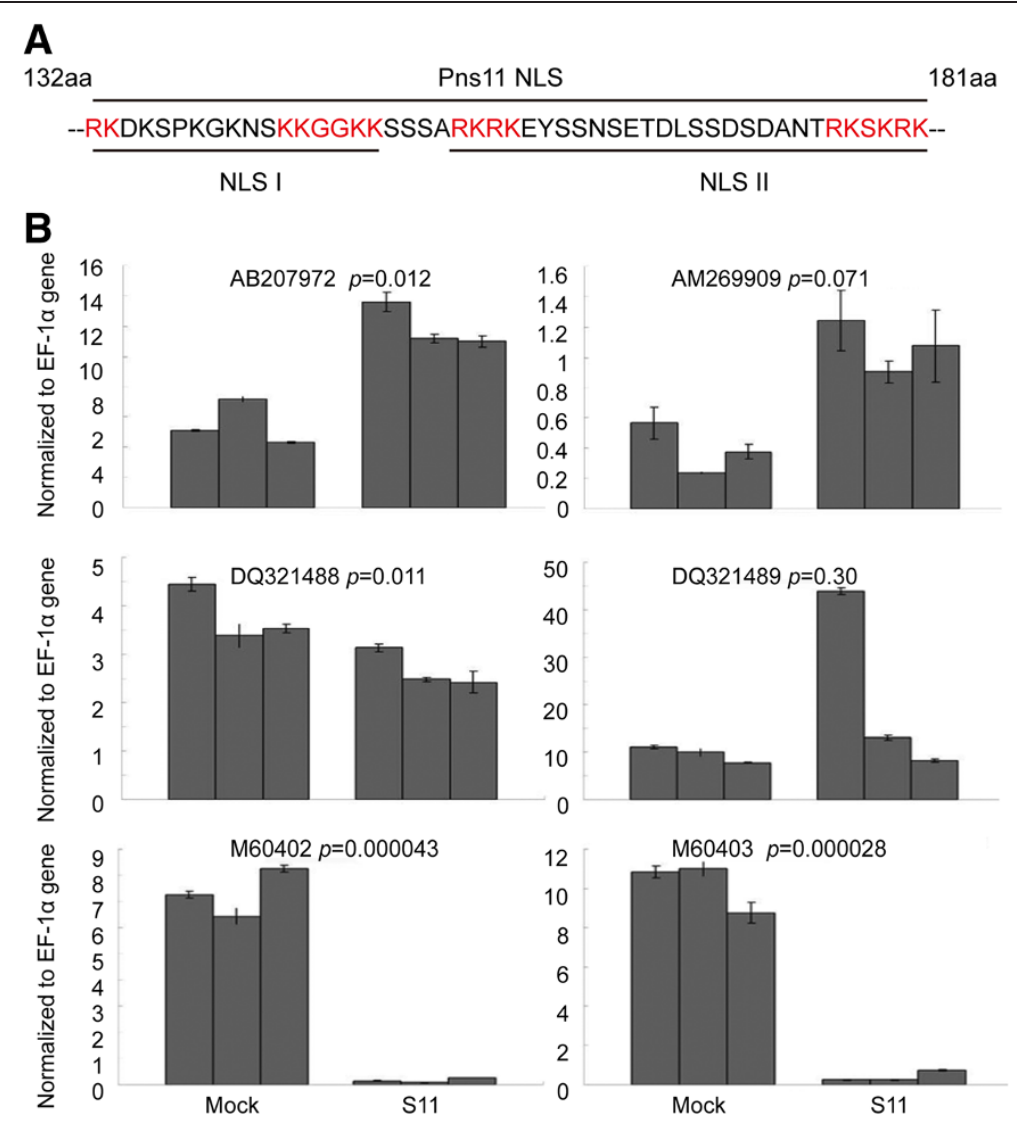

Figure 4 RDV Pns11 regulates the transcript levels of nucleolus-related genes. (A) Schematic representation of Nuclear localization signal (NLS) of RDV Pns11. (B) qRT-PCR was used to monitor the mRNA of nucleolus-related genes. Shown are relative expression ratios to EF-1a. Three replicate experiments were done to reduce biological variation.

$55 \pm 5 \% \mathrm{RH}$ and under natural sunlight. The aerial parts of 8 entire rice plants were sampled randomly and pooled at $22 \mathrm{dpi}$, i.e., $7 \mathrm{~d}$ after appearance of the symptom (the earliest symptoms, i.e. white chlorotic specks in newly developed leaves, appeared at approximately $15 \mathrm{dpi}$ ). The samples were flash-frozen in liquid nitrogen, and stored at $-80^{\circ} \mathrm{C}$ for until use.

\section{RNA preparation and microarray hybridization and scanning}

Total RNA was extracted from the virus- or mockinoculated leaves with TRIzol reagent (Invitrogen). RNA was further purified using RNeasy columns (Qiagen, Valencia, CA, USA). An aliquot of $2 \mu \mathrm{g}$ of total RNA was used to synthesize double-stranded cDNA, then produced biotin-tagged cRNA using MessageAmp ${ }^{\mathrm{Tm}}$ II aRNA Amplification Kit. The resulting bio-tagged cRNA were fragmented to strands of 35 to 200 bases in length according to Affymetrix's protocols. The fragmented cRNA was hybridized to Affymetrix Rice Genome Array containing 51,279 transcripts which includes approximately 48,564 japonica transcripts and 1,260 transcripts representing the indica cultivar (www.affymetrix.com).
Hybridization was performed at $45^{\circ} \mathrm{C}$ with rotation for 16 h (Affymetrix GeneChip Hybridization Oven 640). The GeneChip arrays were washed and then stained (streptavidin-phycoerythrin) on an Affymetrix Fluidics Station 450 followed by scanning on GeneChip Scanner 3000. We altogether used 6 chips to perform the analysis of 6 RNA samples.

\section{Microarray data analysis}

Hybridization data were analyzed using GeneChip Operating software (GCOS 1.4). The scanned images were firstly assessed by visual inspection then analyzed to generate raw data files saved as CEL files using the default setting of GCOS 1.4. A global scaling procedure was performed to normalize the arrays using dChip software. In a comparison analysis, two class unpaired method was applied in the Significant Analysis of Microarray (SAM) software to identify significantly differentially expressed genes between Test group and Control group. All differentially expressed genes were analyzed using the web-based Molecular Annotation System 3.0 (MAS 3.0, http://bioinfo.capitalbio.com/mas/). MAS 2.0 integrate three different open source pathway 
resources-KEGG, BioCarta and GenMAPP. In the MAS 3.0 tool, the pathways and GO were ranked with statistical significance by calculating their $P$-values based on hypergeometric distribution. The GeneChip hybridization and scanning were performed at the Microarray Resource Laboratory at Beijing CapitalBio Corporation, Beijing, China, in which GeneChip microarray service was certificated by Affymetrix.

\section{Transient expression in leaves of $\mathbf{N}$. benthamiana}

Agro-infiltration for transient expression in leaves of Nicotiana benthamiana, Leuzinger was carried out as described [52]. Briefly, individual Agrobacterium GV3101 strains with different expression constructs (or empty vector as control) were co-infiltrated into $N$. benthamiana leaves using a syringe without needle. After 3 day of transient expression, leaves were harvested for RNA extraction.

\section{Real-time PCR assay}

Total RNA used for verification of microarray data was prepared from plants that had been grown independently of those used for isolation of RNA for microarray analysis. One Step RNA PCR Kit (AMV) (TaKaRa, Japan) was used. Gene-specific primers were designed by Primer 5 (for a list of the primers used in this study, see Additional file 3: Table S3) and synthesized by Boya Company (Shanghai, China). Relative quantitation method was used. Rice UBQ11 gene and tobacco EF- $1 \alpha$ were used as the control to normalize all data [53] (for a list of these genes primer sequence, see Additional file 3: Table S3).

\section{Electron microscopy}

For electron microscopy experiments, RDV infected and health rice samples were fixed with $2.5 \%$ glutaraldehyde at $4^{\circ} \mathrm{C}$ overnight, washed in $0.1 \mathrm{M}$ phosphate buffer ( $\mathrm{pH}$ 7.0) for 3 times (15 min per time), and post-fixed in phosphatebuffered 1.0\% OsO4 for $2 \mathrm{~h}$. Then the tissues were bufferwashed, dehydrated with ethanol $(50 \%, 70 \%, 80 \%, 90 \%$, 95\% and 100\%) and embedded in Epon-Araldite. Ultrathin sections $(70-90 \mathrm{~nm})$ were cut with a Reichert ultramicrotome, stained with aqueous uranyl acetate and lead citrate, and examined with a Jeol JEM-1230 transmission electron microscope (Jeol, Tokyo, Japan).

\section{Additional files}

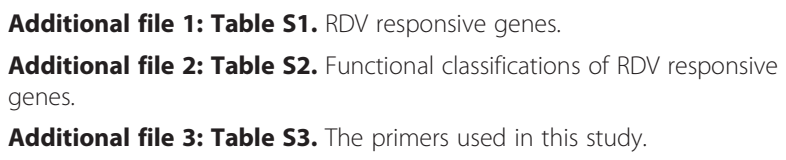

Additional file 3: Table S3. The primers used in this study.

\section{Competing interests}

The authors declare that they have no competing interests.

\section{Authors' contributions}

Conceived and designed the experiments: JGW, ZJW and LHX. Performed the experiments and analyzed the data: JGW, LY, ZGD and KCW. Wrote the paper: JGW, ZGD, LY. All authors read and approved the final manuscript.

\section{Acknowledgements}

We thank Guangpu Li for his critical reading of the manuscript. This work was supported by grants from the National Basic Research Program 973 (2014CB138402, 2013CBA01403 and 2010CB126203), Natural Science Foundation of China (31272018, 31201491 and 31171821), Key Project of the National Research Program of China (2012BAD19B03), Doctoral Fund of Ministry of Education of China (20113515110001, 20113515120004 and 20123515120005), Education department of Fujian Province Office Program (JA11078 and JA11080) and Natural Science Foundation of Fujian Province of China (2011 J05051 and 2013 J01089).

\section{Author details}

${ }^{1}$ Key Laboratory of Plant Virology of Fujian Province, Institute of Plant Virology, Fujian Agriculture and Forestry University, Fuzhou, Fujian 350002, China. ${ }^{2}$ Key Laboratory of Biopesticide and Chemibiology of Ministry of Education, Fujian Agriculture and Forestry University, Fuzhou, Fujian 350002, China. ${ }^{3}$ Peking-Yale Joint Center for Plant Molecular Genetics and Agrobiotechnology, The State Key Laboratory of Protein and Plant Gene Research, College of Life Sciences, Peking University, Beijing 100871, China. ${ }^{4}$ Guangdong Provincial Key Laboratory of High Technology for Plant Protection, Guangzhou 510640, China.

Received: 21 November 2013 Accepted: 22 April 2014 Published: 6 May 2014

\section{References}

1. Whitham SA, Wang Y: Roles for host factors in plant viral pathogenicity. Curr Opin Plant Biol 2004, 7:365-371.

2. Hull R: Matthews' plant virology. San Diego: CA, Academic Press; 2002.

3. Pallas V, García JA: How do plant viruses induce disease? Interactions and interference with host components. J Gen Virol 2011, 92(12):2691-2705.

4. Whitham SA, Yang C, Goodin MM: Global impact: elucidating plant responses to viral infection. Mol Plant Microbe Interact 2006, 19:1207-1215.

5. Wise RP, Moscou MJ, Bogdanove AJ, Whitham SA: Transcript Profiling in Host-Pathogen Interactions. Annu Rev Phytopathol 2007, 45:329-369.

6. Kogovšek P, Pompe-Novak M, Baebler Š, Rotter A, Gow L, Gruden K, Foster GD, Boonham N, Ravnikar M: Aggressive and mild Potato virus $Y$ isolates trigger different specific responses in susceptible potato plants. Plant Pathol 2010, 59(6):1121-1132.

7. Satoh K, Shimizu T, Kondoh H, Hiraguri A, Sasaya T, Choi IR, Omura T, Kikuchi S: Relationship between symptoms and gene expression induced by the infection of three strains of Rice dwarf virus. PLoS One 2011, 6(3):e18094.

8. Hillung J, Cuevas JM, Elena SF: Transcript profiling of different Arabidopsis thaliana ecotypes in response to Tobacco etch potyvirus infection. Front Microbiol 2012, 3:229.

9. Rodrigo G, Carrera J, Ruiz-Ferrer V, del Toro FJ, Llave C, Voinnet O, Elena SF: A meta-analysis reveals the commonalities and differences in Arabidopsis thaliana response to different viral pathogens. PLoS One 2012, 7(7):e40526.

10. Dardick C: Comparative expression profiling of Nicotiana benthamiana leaves systemically infected with three fruit tree viruses. Mol Plant Microbe Interact 2007, 20:1004-1017.

11. Yang C, Guo R, Jie F, Nettleton D, Peng J, Carr T, Yeakley JM, Fan JB, Whitham SA: Spatial analysis of Arabidopsis thaliana gene expression in response to Turnip mosaic virus infection. Mol Plant Microbe Interact 2007, 20:358-370.

12. Satoh K, Kondoh H, Sasaya T, Shimizu T, Choi IR, Omura T, Kikuchi S: Selective modification of rice (Oryza sativa) gene expression by Rice stripe virus infection. J Gen Virol 2010, 91:294-305.

13. Goff SA, Ricke D, Lan TH, Presting G, Wang R, Dunn M, Glazebrook J, Sessions A, Oeller P, Varma H, Hadley D, Hutchison D, Martin C, Katagiri F, Lange BM, Moughamer T, Xia Y, Budworth P, Zhong J, Miguel T, Paszkowski U, Zhang S, Colbert M, Sun WL, Chen L, Cooper B, Park S, Wood TC, Mao L, Quail P: A draft sequence of the rice genome (Oryza sativa L. ssp. japonica). Science 2002, 296:92-100 
14. Hagiwara K, Higashi T, Namba K, Uehara-Ichiki T, Omura T: Assembly of single-shelled cores and double-shelled virus-like particles after baculovirus expression of major structural proteins P3, P7 and P8 of Rice dwarf virus. J Gen Virol 2003, 84:981-984.

15. Miyazaki N, Hagiwara K, Naitow H, Higashi T, Cheng RH, Tsukihara T, Nakagawa A, Omura T: Transcapsidation and the conserved interactions of two major structural proteins of a pair of phytoreoviruses confirm the mechanism of assembly of the outer capsid layer. J Mol Biol 2005, 345:229-237.

16. Wei T, Kikuchi A, Moriyasu Y, Suzuki N, Shimizu T, Hagiwara K, Chen H, Takahashi M, Ichiki-Uehara T, Omura T: The spread of Rice dwarf virus among cells of its insect vector exploits virus-induced tubular structures. J Virol 2006, 80:8593-8602.

17. Chen H, Chen Q, Omura T, Uehara-Ichiki T, Wei T: Sequential infection of Rice dwarf virus in the internal organs of its insect vector after ingestion of virus. Virus Res 2011, 160(1-2):389-394.

18. Hibino H: Biology and epidemiology of rice viruses. Annu Rev Phytopathol 1996, 34(1):249-274.

19. Suzuki N: Molecular analysis of the rice dwarf virus genome. Semin Virol 1995, 6(2):89-95. Academic Press.

20. Omura T, Ishikawa K, Hirano H, Ugaki M, Minobe $Y$, Tsuchizaki T, Kato H: The outer capsid protein of rice dwarf virus is encoded by genome segment S8. J Gen Virol 1989, 70(10):2759-2764.

21. Zheng H, Yu L, Wei C, Hu D, Shen Y, Chen Z, Li Y: Assembly of double-shelled, virus-like particles in transgenic rice plants expressing two major structural proteins of rice dwarf virus. J Virol 2000, 74(20):9808-9810.

22. Zhong B, Kikuchi A, Moriyasu Y, Higashi T, Hagiwara K, Omura T: A minor outer capsid protein, P9, of Rice dwarf virus. Arch Virol 2003, 148(11):2275-2280.

23. Yan J, Tomaru M, Takahashi A, Kimura I, Hibino H, Omura T: P2 protein encoded by genome segment $\mathrm{S} 2$ of rice dwarf phytoreovirus is essential for virus infection. Virology 1996, 224(2):539-541.

24. Zhou ZH, Baker ML, Jiang W, Dougherty M, Jakana J, Dong G, Lu G, Chiu W: Electron cryomicroscopy and bioinformatics suggest protein fold models for rice dwarf virus. Nat Struct Mol Biol 2001, 8(10):868-873.

25. Nakagawa A, Miyazaki N, Taka J, Naitow H, Ogawa A, Fujimoto Z, Mizuno H, Higashi T, Watanabe Y, Omura T, Cheng RH, Tsukihara T: The Atomic Structure of Rice dwarf Virus Reveals the Self-Assembly Mechanism of Component Proteins. Structure 2003, 11(10):1227-1238.

26. Wei T, Shimizu T, Hagiwara K, Kikuchi A, Moriyasu Y, Suzuki N, Chen $H$, Omura T: Pns12 protein of Rice dwarf virus is essential for formation of viroplasms and nucleation of viral-assembly complexes. J Gen Virol 2006 87(2):429-438

27. Wei T, Kikuchi A, Suzuki N, Shimizu T, Hagiwara K, Chen H, Omura T: Pns4 of rice dwarf virus is a phosphoprotein, is localized around the viroplasm matrix, and forms minitubules. Arch Virol 2006, 151(9):1701-1712.

28. Li Y, Bao YM, Wei CH, Kang ZS, Zhong YW, Mao P, Wu G, Chen ZL, Schiemann J, Nelson RS: Rice dwarf phytoreovirus segment S6-encoded nonstructural protein has a cell-to-cell movement function[J]. J Virol 2004, 78(10):5382-5389.

29. Cao X, Zhou P, Zhang X, Zhu S, Zhong X, Xiao Q, Ding B, Li Y: Identification of an RNA silencing suppressor from a plant double-stranded RNA virus. J Virol 2005, 79(20):13018-13027.

30. Zhu S, Gao F, Cao X, Chen M, Ye G, Wei C, Li Y: The rice dwarf virus P2 protein interacts with ent-kaurene oxidases in vivo, leading to reduced biosynthesis of gibberellins and rice dwarf symptoms. Plant Physiol 2005 139(4):1935-1945.

31. Eulgem T, Rushton PJ, Robatzek S, Somssich IE: The WRKY superfamily of plant transcription factors. Trends Plant Sci 2000, 5:199-205.

32. Arora A, Sairam R, Srivastava G: Oxidative stress and antioxidative system in plants. Curr Sci 2002, 82:1227-1238.

33. Berardini TZ, Mundodi S, Reiser $L$, Huala E, Garcia-Hernandez M, Zhang P, Mueller LA, Yoon J, Doyle A, Lander G, Moseyko N, Yoo D, Xu I, Zoeckler B, Montoya M, Miller N, Weems D, Rhee SY: Functional annotation of the Arabidopsis genome using controlled vocabularies. Plant Physiol 2004, 135:745-755.

34. Abel S, Theologis A: A polymorphic bipartite motif signals nuclear targeting of early auxin-inducible proteins related to PS-IAA4 from pea (Pisum sativum). Plant J 1995, 8:87-96.
35. Babu M, Griffiths J, Huang TS, Wang A: Altered gene expression changes in Arabidopsis leaf tissues and protoplasts in response to Plum pox virus infection. BMC Genomics 2008, 9:325.

36. Golem S, Culver JN: Tobacco mosaic virus induced alterations in the gene expression profile of Arabidopsis thaliana. Mol Plant Microbe Interact 2003, 16:681-688.

37. Itaya A, Matsuda Y, Gonzales RA, Nelson RS, Ding B: Potato spindle tuber viroid strains of different pathogenicity induces and suppresses expression of common and unique genes in infected tomato. Mol Plant Microbe Interact 2002, 15:990-999.

38. Ventelon Debout M, Delalande F, Brizard JP, Diemer H, Van Dorsselaer A, Brugidou C: Proteome analysis of cultivar-specific deregulations of Oryza sativa indica and $O$. sativa japonica cellular suspensions undergoing Rice yellow mottle virus infection. Proteomics 2004, 4:216-225.

39. Whitham SA, Quan S, Chang HS, Cooper B, Estes B, Zhu T, Wang X, Hou YM: Diverse RNA viruses elicit the expression of common sets of genes in susceptible Arabidopsis thaliana plants. Plant J 2003, 33:271-283.

40. Shimizu T, Satoh K, Kikuchi S, Omura T: The repression of cell wall-and plastid-related genes and the induction of defense-related genes in rice plants infected with Rice dwarf virus. Mol Plant Microbe Interact 2007, 20:247-254.

41. Hanssen IM, van Esse HP, Ballester AR, Hogewoning SW, Parra NO, Paeleman A, Lievens B, Bovy AG, Thomma BP: Differential tomato transcriptomic responses induced by pepino mosaic virus isolates with differential aggressiveness. Plant Physiol 2011, 156(1):301-318.

42. Maguire BA, Zimmermann RA: The ribosome in focus. Cell 2001, 104:813-816.

43. Green R, Noller HF: Ribosomes and translation. Annu Rev Biochem 1997, 66:679-716

44. Fatica A, Tollervey D: Making ribosomes. Curr Opin Cell Biol 2002, 14:313-318.

45. Gasch AP, Spellman PT, Kao CM, Carmel-Harel O, Eisen MB, Storz G, Botstein $D$, Brown PO: Genomic expression programs in the response of yeast cells to environmental changes. Sci STKE 2000, 11:4241.

46. Kojima H, Suzuki T, Kato T, Enomoto K, Sato S, Kato T, Tabata S, Sáez-Vasquez J, Echeverría M, Nakagawa T, Ishiguro S, Nakamura K: Sugar-inducible expression of the nucleolin-1 gene of Arabidopsis thaliana and its role in ribosome synthesis, growth and development. Plant J 2007, 49:1053-1063.

47. Boisvert FM, Van Koningsbruggen S, Navascués J, Lamond Al: The multifunctional nucleolus. Nat Rev Mol Cell Bio 2007, 8:574-585.

48. Laferté A, Favry E, Sentenac A, Riva M, Carles C, Chédin S: The transcriptional activity of RNA polymerase I is a key determinant for the level of all ribosome components. Genes Dev 2006, 20:2030-2040.

49. Hiscox JA: RNA viruses: hijacking the dynamic nucleolus. Nat Rev Microbiol 2007, 5:119-127.

50. Onodera Y, Haag JR, Ream T, Costa Nunes P, Pontes O, Pikaard CS: The Arabidopsis chromatin-modifying nuclear siRNA pathway involves a nucleolar RNA processing center. Cell 2006, 126:79-92.

51. Henderson IR, Jacobsen SE: Epigenetic inheritance in plants. Nature 2007, 447:418-424.

52. Leuzinger K, Dent M, Hurtado J, Stahnke J, Lai H, Zhou X, Chen Q: Efficient Agroinfiltration of Plants for High-level Transient Expression of Recombinant Proteins. J Vis Exp 2013, 77:e50521.

53. Schmittgen TD, Livak KJ: Analyzing real-time PCR data by the comparative CT method. Nat Protoc 2008, 3:1101-1108.

doi:10.1186/1743-422X-11-81

Cite this article as: Yang et al.: Transcriptome profiling confirmed correlations between symptoms and transcriptional changes in RDV infected rice and revealed nucleolus as a possible target of RDV manipulation. Virology Journal 2014 11:81. 